The University of Maine

\title{
DigitalCommons@UMaine
}

Marine Sciences Faculty Scholarship

School of Marine Sciences

4-1-1998

\section{A Low-Flow Self-Cleaning Drainage System for Fish Rearing Tanks}

D. S. Hagopian

John G. Riley

University of Maine - Main, jriley@maine.edu

Follow this and additional works at: https://digitalcommons.library.umaine.edu/sms_facpub

\section{Repository Citation}

Hagopian, D. S. and Riley, John G., "A Low-Flow Self-Cleaning Drainage System for Fish Rearing Tanks" (1998). Marine Sciences Faculty Scholarship. 3.

https://digitalcommons.library.umaine.edu/sms_facpub/3 


\title{
A Low-Flow Self-Cleaning Drainage System for Fish Rearing Tanks
}

\author{
Daniel S. Hagopian and John G. Riley* \\ Department of Biosystems Science and Engineering \\ University of Maine, Orono, Maine 04469, USA
}

\begin{abstract}
A float-stopper mechanism was designed to drain fish holding tanks directly from the bottom. Unlike traditional, top-drawn standpipe systems, it allows continuous flushing of settled solid waste. It also prevents the accumulation of these wastes between the two standpipes that are used in bottom-drawn, doublewalled standpipe systems. When suspended solids are forced upward between the outer and inner standpipes of such systems, a minimum velocity must be maintained to prevent sediment accumulation. This minimum velocity determines the minimum flow rate through the tank. The system described in this report flushes well over a wide range of flow rates.
\end{abstract}

Most flow-through fish culture tanks are equipped with an overflow device that is designed to flush excrement and regulate water level. In circular tanks, this overflow device is generally in the center; in rectangular tanks, it is at one end. One such apparatus, known as a top-drawn standpipe, works by simple overflow into an extension of the drain. Though simple and inexpensive, this device draws water from the top of the tank and allows solid waste to settle on the bottom and leach soluble waste into the tank water. Cleaning involves the periodic removal of the standpipe or the use of a portable siphon to suction the settled matter. Another common design, known as a doublewalled standpipe (Figure 1), draws water and solid waste from the bottom of the tank into a flushing area between an outer and inner standpipe and then down the inner standpipe. If the presence of a standpipe causes obstruction during harvest, an external standpipe may be used. An external standpipe system modified for fish tanks has been reported in which water flows from the central tank drain to a double-walled standpipe outside the tank (Parker and Jackson 1980). Flow is directed up the inner pipe, through a hole determining tank water depth and down through the annulus between the inner and outer pipes. In a modification of this design (Garling and Masterson 1985) the water moves up the annulus and spills over into the inner pipe. This is similar in function to a standard in-

\footnotetext{
* Corresponding author: riley@apollo.umenfa.maine.edu
}

ternal double-walled standpipe, but with the added advantage of being able to collect and drain solids accumulated at the bottom of the standpipe.

Garrett (1991) described the conversion of standpipes to automatic siphons through the addition of a cover or dome. Bottom water can be drawn by extending the skirt of the dome to the lower part of the tank. An intermediately positioned vent tube prevents the tank from draining completely. The further addition of a vented trap to the drain line extends the range of flows that results in a cyclical siphoning action. This system requires precise dimensioning, does not flush continuously, and produces a relatively large water level variation.

Performance of all of these systems is limited to a relatively low range of flow rates, unless the geometry of the system is changed. For example, in a double-walled standpipe, the velocity of the wastewater in the upward direction is a function of the flushing area and the volumetric flow rate of the fresh water into the tank. Given that the diameter of both standpipes is constant, the velocity is solely dependent on the tank influent rate. When the flow rate falls below a critical level so as to make the settling velocity of the solid waste greater than the upward velocity of the wastewater, excess feed and feces accumulate in the flushing area. A double standpipe that is small enough to provide this velocity for the lowest expected flow does not work well at higher flow rates, and it is impractical to have a range of sizes available. Cleaning is periodically required through the removal of the inner standpipe. This partially drains the tank, can resuspend some sludge beyond the outer standpipe, and can stress the fish. Top-drawn, double-walled, and siphon standpipes can degrade water quality by not disposing of solid waste as soon as it reaches the bottom.

A limited supply of well water in one of our laboratories prompted us to design a new low-flow drainage system (Figure 2). The proposed system consists of a float connected by a rod to a stopper, and a standpipe. The rod is threaded at each end and a rigid foam float is attached to one end by a 


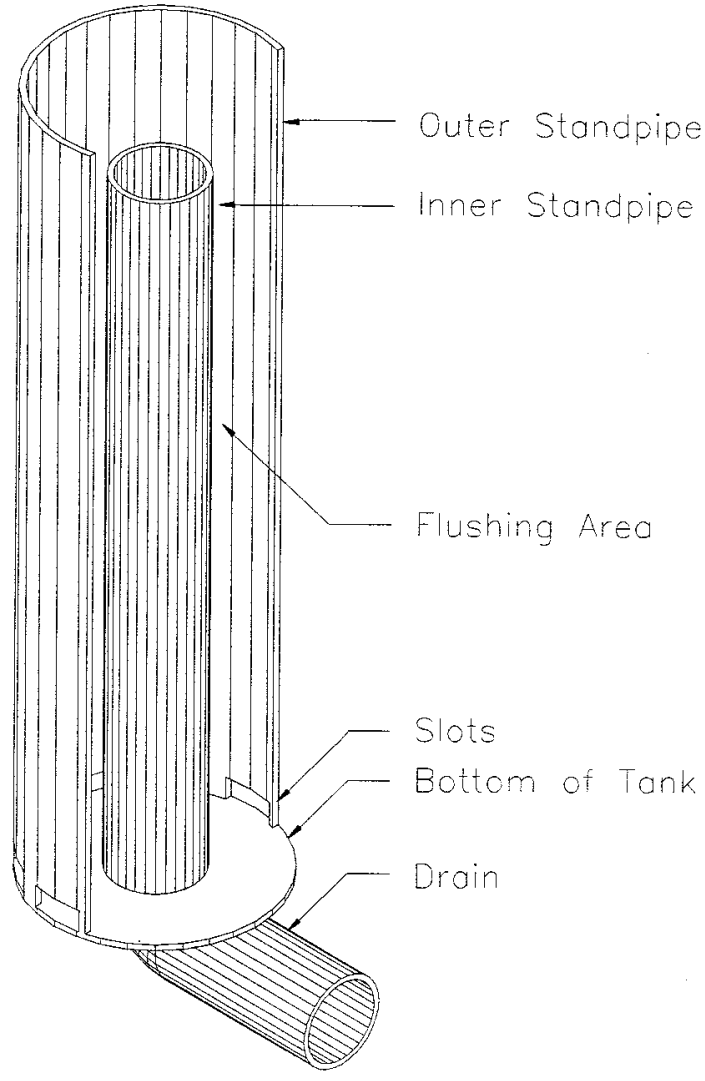

FIGURE 1.-Typical double-walled drainage system.

wing nut (for easy removal during harvesting of fish) and washer on top and bottom. All metal components should preferably be stainless steel. Large washers should be used to prevent the foam float from being overcompressed. The stopper may be made of a rubber ball, a pipette suction cap, a chef's baster bulb, a mason's blower bulb, or a toilet tank plug, depending on the required size. If a solid toy ball is used, it is drilled and tapped for attachment to the other end of the rod. If a hollow device (e.g., a pipette suction cap) is used, the mouth of the bulb is filled with waterproof adhesive to fix it to the rod. A hole should be drilled in the bulb to allow it to fill with water and have sufficient weight to seal the drain. The stopper diameter should be slightly smaller than the inner diameter of the standpipe.

The rod and stopper are placed inside a polyvinyl chloride (PVC) pipe that has an outer diameter equal to the inner diameter of the drain at the bottom of the tank. The top of the pipe has a cap with a hole in the middle to guide the nonthreaded portion of the rod. The guide hole should be large enough to allow the rod to move freely without binding but not so large as to let a substantial amount of water through. At the bottom of the pipe, slots are milled as shown in Figure 2. The pipe is placed (not glued) in the drain as a standpipe. It is critical that the horizontal slots be parallel to the bottom of the tank and that they not be too high. A higher flushing current on the bottom of the tank will be achieved with a smaller slot area. However, the slots must be large enough to allow solid waste particles to pass through and to allow drainage to keep up with the maximum influent rate. If the tank is to hold small fish, it will be necessary to glue appropriate size screening over the slots. It is necessary to decrease the diameter of the drain below the standpipe with a gradual-reducing coupler or a sudden-reducing coupler to a diameter less than that of the stopper in order to give it a seat. To avoid an overflow, the position of the float may be adjusted so that its top is at the maximum desired water level when the system is at equilibrium with a maximum influent rate. The standpipe should be cut such that its top is a few inches below the float when the stopper is seated.

The forces pushing the stopper down are a combination of the weight of the stopper-rod-float assembly, the static pressure of the water acting across the reduced drain area, and a friction force associated with the deformation of a wedged-in stopper. The latter figure is empirically related to the geometry of the reducer (i.e., sudden or gradual) and the shape and material of the stopper. As influent fills the tank, the float becomes partially submerged and an upward force builds. At some point, the buoyancy of the float overcomes the static downward force and unplugs the drain. Once the stopper is lifted off its seat, the flow of water down the drain causes a negative pressure on the bottom of the stopper. Also, drag is encountered as water turbulently rushes from the standpipe slots, around the stopper, and down the drain. As the stopper rises, forces pulling downward drop off rapidly. This happens because the annular aperture between the stopper and the drain increases in size and the negative pressure acting on the bottom of the stopper is reduced. Also, if the stopper rises above the slots in the standpipe, water would no longer flow onto the stopper, and drag would be reduced.

As water drains from the tank and the level falls, the stopper moves downward to close the outlet, and the cycle is repeated. We have been able to design a system in which the stopper remains 


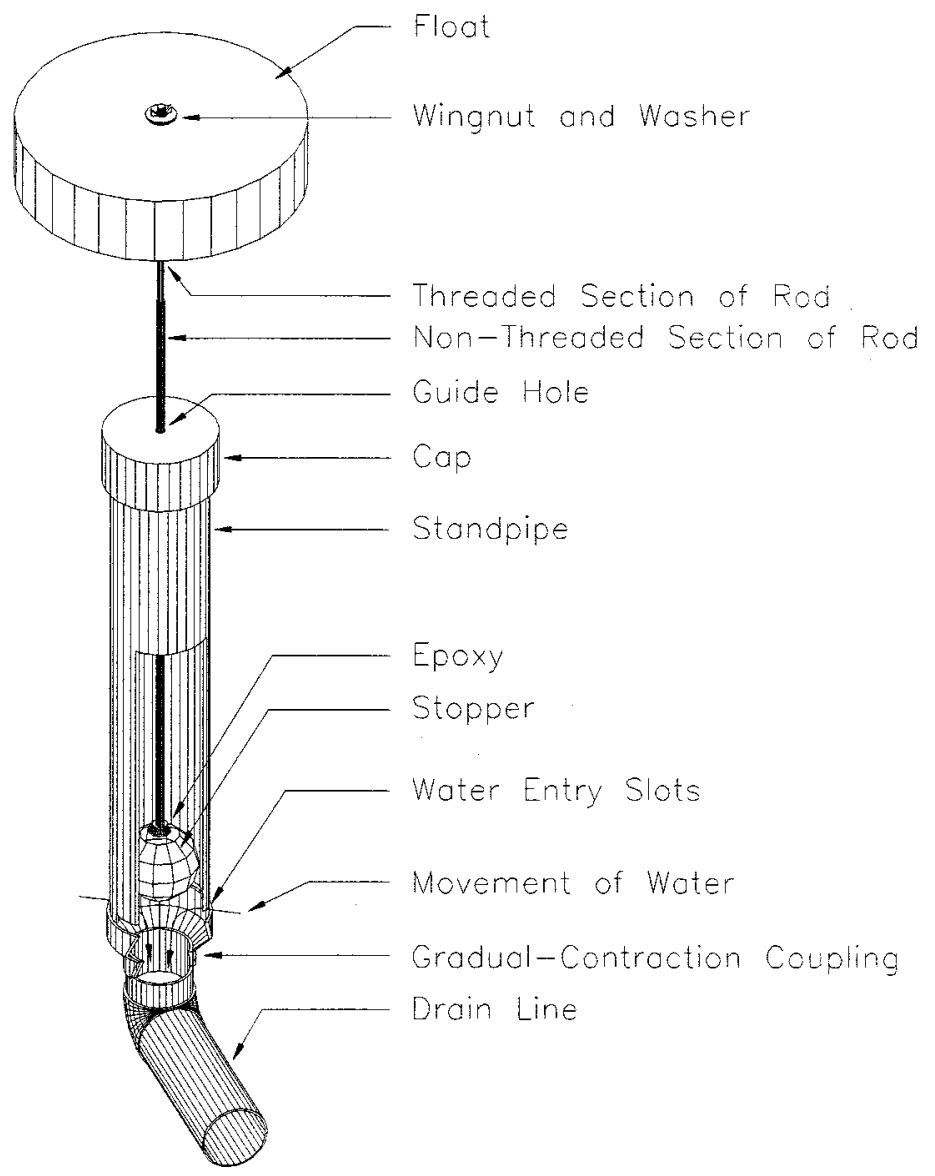

FIGURE 2.-Proposed float-stopper drainage system.

slightly open in a stationary position, producing a constant outflow. However, we have found that if the stopper opens and closes the drain at short intervals, there is a better flushing of solids at low influent rates. Site-specific requirements, static stopper distortion, dynamic drag, and negative pressure all make an analytical design difficult. An empirical approach is recommended. We have constructed float-stopper drainage systems with 1-, 2-, and 3-in standpipes. Specifications for the 3-in system are as follows:

$\begin{array}{ll}\text { Standpipe } & \text { 27-in length of 3-in PVC pipe } \\ \text { Pipe cap } & \text { 3-in PVC } \\ \text { Reducer } & \text { 3-in to 2-in PVC threaded coupler } \\ \text { Rod } & \text { 3-ft length of 3/8-in diameter } \\ & \text { stainless steel } \\ \text { Stopper } & \text { 2.5-in-diameter rubber ball } \\ \text { Float } & \text { Disk-shaped polystyrene block, } \\ & \text { 17.5-in diameter } \times 3.5 \text {-in height }\end{array}$

Tank

Fiberglass, 6-ft diameter $\times \sim 34$-in water depth

Initial tests of this apparatus have been encouraging. The 3-in system completely removed solid waste from a flat-bottomed, circular 600-gal tank that held 25 rainbow trout Oncorhynchus mykiss ( $\sim 2 \mathrm{lb}$ each). Influent rates ranged from $50 \mathrm{gal} /$ min down to $1.8 \mathrm{gal} / \mathrm{min}$. The system provides minimal water level variation $( \pm 1.5$ in) over this range of flow rates and operates relatively maintenance free. Trials have shown that a stopper that enters a tapered drain line coupler (i.e., gradualreducing coupler) usually comes to equilibrium with a smooth, constant flow of water. An abrupt change in the drain diameter (i.e., sudden-reducing coupler), on the other hand, is more likely to result in a rapidly oscillating, on-off drainage.

Although many provisions were made to lessen the potential for fish loss, there remains a slight 
chance of the tank draining completely under the following circumstances: (1) the rod bends above the cap, (2) an object enters the standpipe slots and does not go down the drain, (3) the top of the rod or wing nut gets hung up on something (e.g., the mesh of a net covering the tank), or (4) the stopper deteriorates and loses its ability to seal the drain.

In each case, the problem would probably not manifest itself unless the influent water was shut off. It is recommended that the water be purposely shut off periodically to check the stopper seal on the drain. However, whatever type of standpipe is used, it is generally prudent to use a level sensor to alert personnel to a flow problem.

Acknowledgments.-The authors thank Ben
Dresser for technical assistance. This research was funded by the Maine Agricultural and Forest Experiment Station, MAFES publication 2172.

\section{References}

Garling, D. L., and M. F. Masterson. 1985. An inexpensive external drainpipe system. Progressive Fish-Culturist 47:128-129.

Garrett, R. E. 1991. Principles of siphons. Journal of the World Aquaculture Society 22:1-9.

Parker, N. C., and G. A. Jackson. 1980. External standpipe drain system for fish tanks. Progressive FishCulturist 42:53-54.

Received December 24, 1996 Accepted October 31, 1997 